\title{
Profile of whole blood gene expression following immune stimulation in a wild passerine
}

Richard Meitern ${ }^{1 *}$, Reidar Andreson ${ }^{2}$ and Peeter Hõrak

\begin{abstract}
Background: Immunoecology aims to explain variation among hosts in the strength and efficacy of immunological defences in natural populations. This requires development of biomarkers of the activation of the immune system so that they can be collected non-lethally and sampled from small amounts of easily obtainable tissue. We used transcriptome profiling in wild greenfinches (Carduelis chloris) to detect whole blood transcripts that most profoundly indicate upregulation of antimicrobial defences during acute phase response. The more general aim of this study was to obtain a functional annotation of a substantial portion of the greenfinch transcriptome that would enable to gain access to more specific genomic tools in subsequent studies. The birds received either bacterial lipopolysaccharide or saline injections and RNA-seq transcriptional profiling was performed $12 \mathrm{~h}$ after treatment to provide initial functional annotation of the transcriptome and assess whole blood response to immune stimulation.

Results: A total of 66,084 transcripts were obtained from de novo Trinty assembly, out of which 23,153 could be functionally annotated. Only 1,911 of these were significantly upregulated or downregulated. The manipulation caused marked upregulation of several transcripts related to immune activation. These included avian-specific antimicrobial agents avidin and gallinacin, but also some more general host response genes, such as serum amyloid A protein, lymphocyte antigen 75 and copper-transporting ATPase 1. However, links with avian immunity for most differentially regulated transcripts remained rather hypothetical, as a large set of differentially expressed transcripts lacked functional annotation.

Conclusions: This appears to be the first large scale transcriptional profiling of immune function in passerine birds. The transcriptomic data obtained suggest novel markers for the assessment of the immunological state of wild passerines. Characterizing the function of those possible novel infection markers would assist future vertebrate genome annotation. The extensive sequence information collected enables to identify possible target and housekeeping genes needed to gain access to more specific genomic tools in future studies.
\end{abstract}

\section{Background}

Parasites and pathogens are recognized as a major evolutionary force, and all living organisms face a continual struggle to fend off immunological insults within their environment reviewed in [1,2]. A host's ability to resist infection is therefore often seen as a major determinant of fitness in nature [3]. Yet most of our knowledge about the function and dynamics of immune responses comes from laboratory studies of inbred mice in highly controlled environments with limited exposure to infection. Natural populations, on the other hand, exhibit

\footnotetext{
* Correspondence: richard.meitern@ut.ee

${ }^{1}$ Department of Zoology, Institute of Ecology and Earth Sciences, Tartu University, Vanemuise 46, 51014 Tartu, Estonia

Full list of author information is available at the end of the article
}

wide genetic and environmental diversity [4]. Immunoecology links patterns of immune responses and disease susceptibility to individual fitness consequences [5-7], and asks how immune defences have evolved, are used and are optimized in different environments, ecological settings and lineages. Integrating genomic information into immunoecological research enables to see how variation in genetic background can be linked to phenotypic variation, allowing insight into genetic architecture of protective immune phenotypes [4,8]. However, wild vertebrate species with well-understood ecology typically lack genome sequences [9]. To obtain speciesspecific nucleotide sequences without prohibitive costs and time required for sequencing of a complete genome, gene expression data can be used [10]. Transcriptome 
data provides direct insight into the functional part of the genome, enabling one to study the genetic basis of phenotypic variation in species that lack reference sequences [11]. Consequently, sequencing the normalized mRNA pools of various non-model organisms has become increasingly popular amongst researchers ([11-15] and references therein).

While greater discovery of rare transcripts can be made by sequencing normalized mRNA pools, sequencing non-normalized samples enables one to obtain valuable information about changes in gene expression [13]. Nevertheless, experiments looking at large scale transcriptional changes in ecological studies are generally restricted to species for which microarrays could be developed [16,17]. However, obtaining data of gene expression via sequencing rather than using specific microarray hybridization would not only allow detection of novel transcripts and retrieve species-specific data, but would reduce bias in gene expression profiling from possible cross-species hybridization mismatches $[16,18,19]$.

Immunoecological studies generally require non-invasive markers to allow longitudinal sampling from small amount of easily obtainable tissue [4]. Hence characterizing gene expression of blood cells seems to be the choice in this field. So far, the majority of studies that have looked at transcriptional changes following an experimentally induced immune challenge in live animals have focused on a few transcripts that are well known to be associated with an immune response [20-24]. However, few of these studies have highlighted large numbers of genes not specifically involved in immune function $[17,25,26]$. Characterizing the full transcriptional profile following an immune challenge would thus facilitate the design of novel and more accurate primers for genes related to immune system activation.

The study species greenfinch, Carduelis chloris, is an extensively studied gregarious seed-eating passerine of the Palearctic region that diverged from zebra finches, the closest species with an assembled genome, 25 MY ago [27]. Plumage coloration of greenfinches is sexually selected [28] and sensitive to infections [29-31]. Greenfinches tolerate captivity well [32], which facilitates research in ecophysiology, e.g. [33], immune function $[34,35]$, chronic infections [36,37], oxidative stress [38], behaviour [39] and personality [40]. Currently there is no greenfinch gene expression data in the NCBI nucleotide database. However, such data are required for selecting appropriate qPCR control and target genes in studies of gene expression. Adding transcriptome data to current information about the physiology and ecology of greenfinches would thus facilitate further immunoecological research on this avian model.

We have compared transcriptome expression in immunechallenged vs sham-injected greenfinches $12 \mathrm{~h}$ after injection with bacterial lipopolysaccharides (LPS) to see which genes were expressed in the blood during the acute phase response (APR). LPS is a part of the cell wall of gram-negative bacteria, which are universally present in most environments. A challenge with LPS mimics a functionally relevant natural situation. Injection of LPS initiates APR by mimicking the first stages of a bacterial infection without actually resulting in sustained disease reviewed in [41]. The APR has become an important tool in examining the effects of immune activation on the performance and functionality of other condition-dependent life-history traits reviewed in [42]. It constitutes energetically the most expensive part of an immune response [43], characterized by hyperthermia, the release of endogenous proinflammatory cytokines, the release of glucocorticoids and the presentation of sickness behaviour reviewed in [42]. Specifically, we aimed to (i) obtain a functional annotation of a substantial portion of the greenfinch transcriptome, and (ii) identify transcripts significantly upregulated or downregulated in the blood following an immune challenge.

\section{Methods}

Female wild greenfinches were captured in mist-nets at bird feeders in a garden in the city of Tartu, Estonia $\left(58^{\circ} 22^{\prime} \mathrm{N}, 26^{\circ} 43^{\prime} \mathrm{E}\right)$ on 7 th, 8th, 14th and 15th January 2013. The birds were housed indoors in individual cages $(27 \times 51 \times 55 \mathrm{~cm})$ with sand-covered floors in a single room where they could see their neighbours. The average temperature in the aviary during the experiment was $13.4 \pm 1.3^{\circ} \mathrm{C}$ (average values are given with \pm standard deviation). The birds were supplied ad libitum with sunflower seeds and tap water, and were exposed to a natural day-length cycle using artificial lighting by luminophore tubes. They were released back to their natural habitat on 14th March 2013. The study was conducted under license from the Estonian Ministry of the Environment (Licence \# 1-4.1/11/100, issued on 23rd March 2011), and the experiment was approved by the Committee of Animal Experiments at the Estonian Ministry of Agriculture (decision \# 95, issued on 17th January 2012).

Prior to the experiment the birds were divided into 2 equal-sized groups on the basis of similar age (yearlings vs. older, determined on the basis of plumage characteristics) and body mass, recorded on 11th March. On the evening of 12th March after the lights had been switched off, four birds received an injection of $0.1 \mathrm{mg}$ E. coli LPS (strain 055:B5, Sigma L2880) in $40 \mu \mathrm{L}$ sterile isotonic saline into the pectoralis muscle. The dose was based on previous findings of greenfinches where similar treatment affected a number of biochemical health state indices [44]. The remaining four birds received $40 \mu \mathrm{L}$ isotonic saline injections. Twelve $\mathrm{h}$ after injection blood samples were taken and $0.1 \mathrm{ml}$ of whole blood was immediately added 
to $0.75 \mathrm{ml}$ Tri Reagent BD (Sigma), mixed and stored at $-80 \mathrm{C}$. For the extraction of total RNA, a combination of Tri Reagent BD and Quigen RNeasy Mini kit was used with modifications described elsewhere [45]. The samples were DNase treated according to the instructions of Quigen RNeasy Mini kit. The quality and quantity of the extracted RNA was assessed by Nanodrop and Agilent 2100, respectively. On average $3.8 \pm 1.6 \mu \mathrm{g}$ total RNA with a mean RIN value of $8.8 \pm 0.7$ was extracted per sample. The total RNA was sent to BaseClear BV (Leiden, Netherlands) for subsequent mRNA extraction, cDNA library construction, sequencing and de novo assembly of the filtered reads. Per sample paired-end 51 cycle run was run using a Illumina HiSeq2500 sequencer. Reads in FASTQ format were generated using a Illumina Casava pipeline (version 1.8.3). Initial quality assessment was based on data passing the Illumina Chastity filtering, with $\sim 90 \%$ of the reads passing this step. From the remaining reads, $\sim 1 \%$ containing adapters (generally considered of low quality) and/or PhiX control signal were removed at Baseclear BV. The second quality assessment was based on the remaining reads $(500$ million) using the FASTQC quality control tool (version 0.10.0). The average Phred quality score for the reads was $37 \pm 0.05$, with a read length of $51 \mathrm{bp}$. The average insert size was $134 \pm 10 \mathrm{bp}$. The sequence reads of individual samples were pooled and assembled using Trinity [46], which is specifically designed for de novo assembly of transcriptomes. The assembly has been deposited in the Transcriptome Shotgun Assembly (TSA) database at DDBJ/EMBL/GenBank (accession no. GBCG00000000), the version described here being the first version, GBCG01000000. The following bioinformatics workflow is summarized in Figure 1. The resulting contigs were annotated with Rapsearch2 [47], using the UniprotSwissprot and NCBI nr database. Best match was determined comparing bitscores of different alignments. Gene Ontology (GO) terms of the annotated transcripts were obtained and GOSlimViewer [48] was used to generate a high level summary of the GO terms using Generic
GO slim Developed by the GO Consortium. The BLAST program [49] (version 2.2.28+) with default parameters was used for BLASTN homology searches against known protein coding DNA (cDNA) and full genome libraries (obtained from Ensembl) of chicken and zebra finch. Coverage of a BLASTN search was calculated by dividing alignment length by transcript length and multiplying by 100 . The BLASTX homology search against Core Eukaryotic Genes (CEGs), which consist of 458 conserved genes [50], was used to assess the completeness of the assembled transcriptome. For comparing the data of differentially regulated transcripts with human common host response genes described by Jenner and Young [51], gene name synonyms were obtained from NCBI (ftp.ncbi. nlm.nih.gov/gene/DATA/gene_info.gz). All database comparisons used Microsoft Access 2007.

To assess the RNA expression of experimental groups, the reads from each sample were mapped to the assembled transcriptome. Treatment groups were compared by Baggerly's test [52], which calculates the proportion of counts in a group of samples against those of another group, and is suitable for cases where replicates are available in the groups. In the data, a positive fold change indicates upregulation following immune challenge. Expression difference was calculated for all of the contigs. Expression levels presented refer to RPKM (Reads Per Kilobase of transcript per Million mapped reads) separately for both treatment groups.

\section{Results}

De novo assembly resulted in 66,084 sequences with a total length of 39.3 million and mean length of $596 \mathrm{bp}$ $(\mathrm{N} 50=803, \mathrm{~N} 25=1678)$. The longest and shortest sequences assembled were 13,752 and $201 \mathrm{bp}$, respectively. Twelve sequences from this dataset were omitted after passing the sequences through NCBI TSA submission contamination screen, on suspicion of bacterial contamination. Around a third of the resulting assembled contigs were successfully annotated using Uniprot-SwissProt $(23,151$ annotations) with an average identity of $69 \pm$

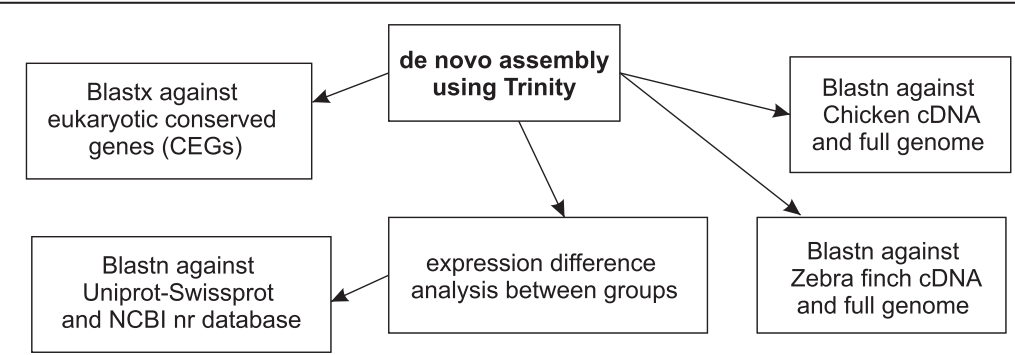

Figure 1 Summary of the bioinformatics workflow. After de novo assembly of sequencing data, individual reads were mapped to the obtained assembly i.e. transcript abundance data were calculated per individual. Subsequently expression difference analysis and BLAST searches against Uniprot-Swissprot and NCBI non-redundant database were preformed. BLAST searches were also run against both chicken and zebra finch coding DNA and genome sequences (retrieved from Ensembl). 
$21 \%$ (the full list of annotated transcripts is given in Additional file 1: Table S1). Only 11,936 of these were unique genes. Setting the e-value to $1 \mathrm{E}-20$ reduced this number to 7,135 (average identity $84 \pm 13 \%$, average coverage $43 \pm 35 \%)$. NCBI $\mathrm{nr}$ database enabled to annotate a similar number $(24,553)$ of contigs with an average identity of $81 \pm 23 \%$. Altogether, $\sim 44 \%(28,925)$ of the assembled contigs found a hit from one or both of the abovementioned databases.

BLASTX results indicated that all of the 458 CEGs were present in our assembled transcriptome, giving an average coverage of $98.3 \pm 3.4 \%$ at e-value threshold 1E20 . Nevertheless only $\sim 25 \%$ of the de novo assembled sequences mapped to zebra finch and/or chicken cDNA databases (Figure 2). However, these 25\% covered almost half of all the sequences available in the datasets (50\% of zebra finch and $42 \%$ of chicken cDNAs). The average identities were $96.1 \pm 2.8 \%$ for zebra finch and $89 \pm 4.7 \%$ for chicken cDNA sequences. For both species, $\sim 65 \%$ of the assemblies had coverage of $>80 \%$, indicating good homology. In addition, $86 \%$ of the 66,072 contigs mapped to zebra finch genome ( $70 \%$ of those had coverage of $>$ $80 \%)$. Strangely, mapping to the chicken genome succeeded only for $27 \%$ of the contigs, $24 \%$ of which had coverage of $>80 \%$. However, changing the BLASTN run parameters (word size reduced to 7 , e-value $1 \mathrm{E}-03$ ) resulted in mapping $65 \%$ of the contigs. Only $17 \%$ of these had coverage of $>80 \%$.

As anticipated, the highest expression was detected for different hemoglobin subunits which made up more

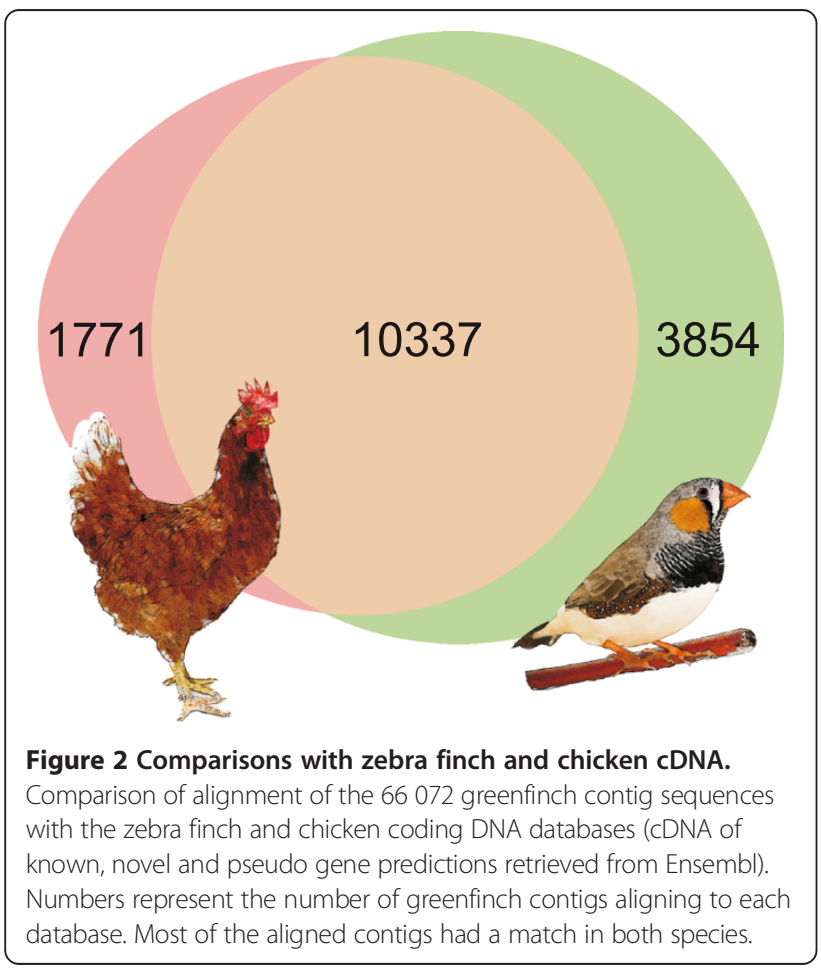

than a third from the total unique gene reads per individual. Other highly expressed transcripts (RPKM >1000) included ferritin, histone H5, carbonic anhydrase and RNAs coding various ribosomal proteins, but also included three unannotated transcripts.

LPS-injected birds lost significantly more body weight (change in body mass $-0.6 \pm 0.3 \mathrm{~g}$ in LPS injected birds vs $0.4 \pm 0.4 \mathrm{~g}$ in saline injected birds, $\mathrm{t}=3.95, \mathrm{df}=6, \mathrm{p}=$ 0.008 ), and the experimental procedure significantly affected 1,911 transcripts (absolute fold change $>2$, Baggerley's test P-value $<0.01)$, of which only 466 (420 unique genes) had been successfully annotated using Uniprot-SwissProt. The summary GO annotation of biological processes of those differentially regulated transcripts is given in Figure 3. Comparing the list of differentially expressed transcripts with 511 human common host response genes showed only 7 shared genes - apolipoprotein B (APOB), DNA polymerase subunit gamma (POLG), interleukin 1 receptor antagonist (IL1RN), cell cycle checkpoint protein (RAD1), zinc finger protein, Y-linked (ZFY), serum amyloid A protein (SAA) and interleukin 8 (IL8). In total, nearly half (247) of the human common host response genes were present in the complete dataset. Chicken cecum transcriptome profile during innate immune response [53,54] shared upregulation of IL8, SAA, avidin (AVID) and protein MRP-126 (M126) with the current study.

Considering only transcripts with reasonably high expression (RPKM $>8$, i.e. $>1$ RPKM per bird), only 54 transcripts were differentially regulated (absolute fold change $>2$, Baggerley's test P-value $<0.001$ ), of which 23 had been previously annotated. Twelve of these annotations were considered sufficiently reliable (identity over $50 \%$, e-value under $1 \mathrm{E}-20$ ). Fold change and possible function of these 12 transcripts are shown in Table 1. A full list of expression values, test statistics and fold-changes can be accessed from Additional file 1: Table S1.

\section{Discussion}

This greenfinch gene expression data enabled us to identify possible target and housekeeping genes needed to access to more specific genomic tools in subsequent studies. Although the results incorporate a high number of unreliably annotated sequences, evaluating CEGs from the dataset suggest nearly complete transcriptome coverage. The highly expressed sequences for which no match was found could represent non-coding RNAs that cannot be identified. Even in mammals, a large part of regulatory RNAs is still unidentified [68], so that 40\% of reads map to unannotated regions [16]. Considering also the general bias towards mammalian annotations in public databases, the annotation of only $1 / 3$ of the assembled transcripts is not surprising. Mapping our assembly to zebra finch cDNA database showed similar 


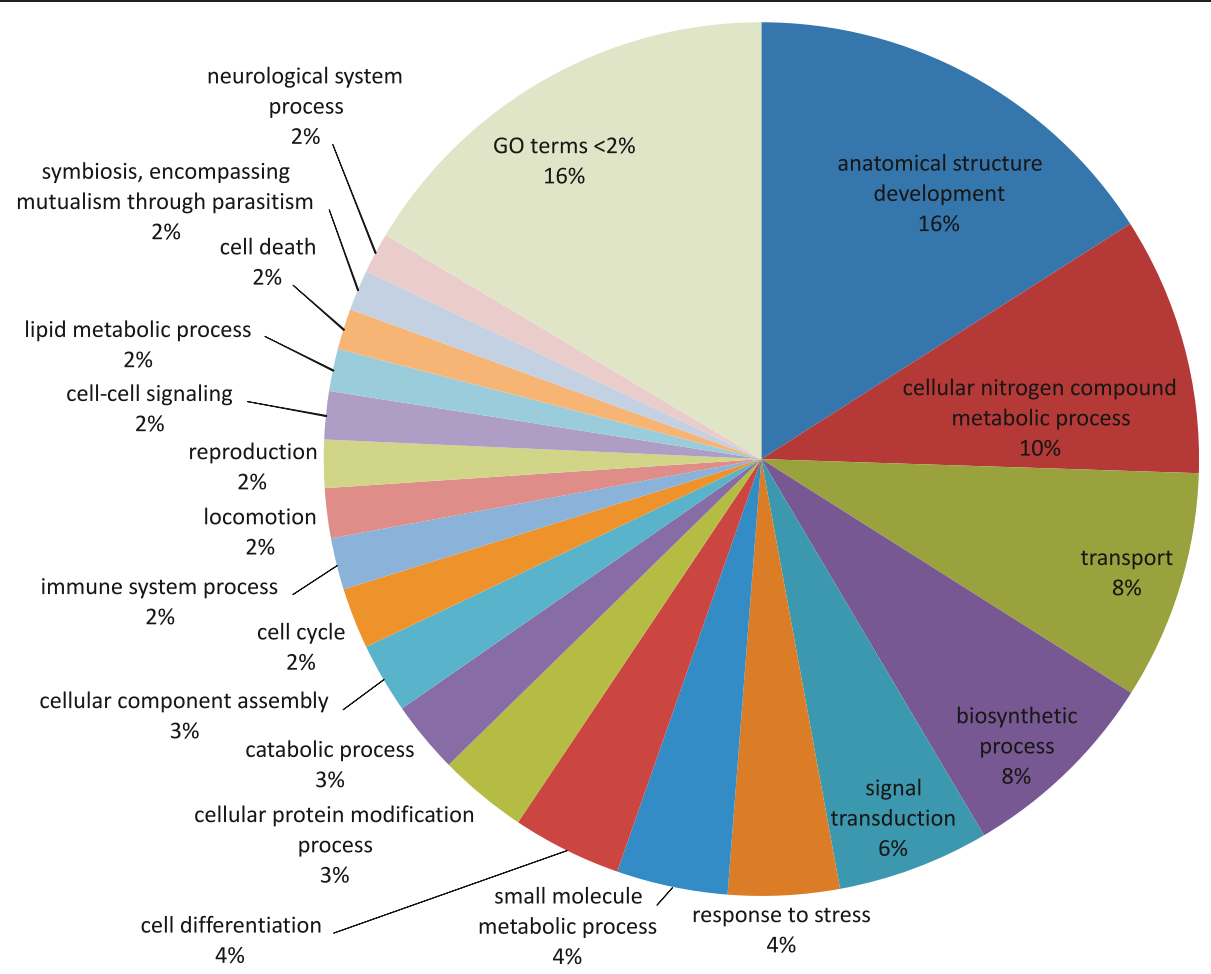

Figure 3 Gene ontology classification of differentially regulated transcripts. Biological process gene ontology (GO) terms of the annotated transcripts with absolute fold change $>2$, Baggerley's test P-value $<0.01$ (420 genes). This high level summary was obtained using GOSlimViewer [48] with the Generic GO slim set of GO terms developed by the GO Consortium (http://www.geneontology.org). Terms that made up $<2 \%$ were merged with their parent term. The distribution indicates increase in catabolic processes and biosynthesis.

coverage. Moreover, the majority of transcripts easily mapped to the zebra finch genome, whereas mapping to the chicken genome was rather poor. This discrepancy may reflect differences in phylogenetic distance between the species, as reducing word size improved mapping to the chicken genome. However, problems in short read data assembly are also well known [69]. Therefore reliable annotations could be expected primarily for highly expressed sequences.

Differential expression data showed the transcripts most strongly affected by immune stimulation. To our knowledge, this kind of large scale profiling of immune function has not been done previously on greenfinches or any other passerines. Similarly to immune stimulation of zebrafish (Danio rerio) embryos [70], a large proportion ( 70\%) of differentially expressed sequences lacked a functional annotation, even when only those with higher expression levels were considered. These unannotated transcripts may represent novel immune response genes in birds that need to be checked for this function in subsequent studies.

Although the differentially regulated annotated transcripts with reasonably high expression levels could be tied to immune response or related processes (Table 1), in some cases their exact source and participation in avian immunity remains unclear. This applies especially to the vps26 family protein, DSCR3. Upregulation of mammalian vps26 promotes transcytosis of polymeric immunoglobulin receptor - polymeric immunoglobulin A complex in epithelial cells [66]. However, its upregulation following an in vivo immune challenge has not been previously reported. LPS-induced regulation of HPS5 is quite intriguing. HPS5 (Ruby eye-2) is an ubiquitously expressed protein [71] in vivo related to melanocyte differentiation and eumelanin synthesis [60]. Its absence influences the distribution of CD63 [72], the platelet activation antigen essential for leukocyte recruitment [73]. Hence, upregulation of HPS5 during the greenfinch immune response suggests the genes involvement in linking melanin-based traits and immune function - a concept proposed in vertebrates [74]. However, the pleiotropic effect of HPS5 in the avian model systems remains to be established.

Upregulation of a conserved transcription initiation factor TFIIH core subunit, GTFIH1 (p62), as well as the downregulation of SLC38A2 could reflect a global change in cell functioning. Differential expression of SLC38A2 is expected following enhanced proteolysis that causes an increase in transporter substrate amino acids known to inhibit the transcription of SLC38A2 [75] and upregulation 
Table 1 Most significant differentially regulated transcripts

\begin{tabular}{|c|c|c|c|c|c|c|c|c|c|}
\hline \multicolumn{4}{|c|}{ Uniprot-SwissProt annotation } & \multicolumn{2}{|c|}{ RPKM } & \multirow[b]{2}{*}{$\begin{array}{l}\text { Fold } \\
\text { change }\end{array}$} & \multicolumn{2}{|c|}{ Baggerley's test } & \multirow[b]{2}{*}{ Known or possible functions } \\
\hline Gene name & Accession & Identity \% & Transcript name & $\mathrm{LPS} \pm \mathrm{SD}$ & Saline \pm SD & & $\begin{array}{c}\text { Test } \\
\text { statistic }\end{array}$ & P-value & \\
\hline$\overline{\text { GAL2 }}$ & P46158 & 91 & $\begin{array}{c}\text { Gallinacin-2 } \\
\text { (Beta-defensin 2) }\end{array}$ & $4.7 \pm 2.3$ & $0.02 \pm 0.03$ & 221.00 & 21.4 & $<0.00001$ & antimicrobial activity [55] \\
\hline AVID & P02701 & 70 & Avidin & $12.3 \pm 5$ & $0.2 \pm 0.3$ & 53.26 & 4.8 & $<0.00001$ & antimicrobial activity [56] \\
\hline SAA & P02740 & 73 & $\begin{array}{l}\text { Serum amyloid } \\
\text { A protein }\end{array}$ & $16.1 \pm 8.3$ & $0.6 \pm 0.3$ & 28.63 & 3.8 & 0.00017 & $\begin{array}{l}\text { chemoattractant for immune } \\
\text { cells, induction of pro-inflammatory } \\
\text { cytokines and extracellular matrix } \\
\text { degrading enzymes }[53,57]\end{array}$ \\
\hline M126 & P28318 & 78 & Protein MRP-126 & $183 \pm 76.8$ & $24.1 \pm 28.8$ & 7.58 & 3.9 & 0.00011 & $\begin{array}{c}\text { leukocyte chemoattractant, } \\
\text { oxidant scavenging, } \\
\text { antimicrobial activity [58] }\end{array}$ \\
\hline DNAJC12 & Q9UKB3 & 78 & $\begin{array}{l}\text { DnaJ (Hsp40) } \\
\text { homolog, } \\
\text { subfamily C } 12\end{array}$ & $10.4 \pm 5.7$ & $4.5 \pm 2.4$ & 2.30 & 3.7 & 0.00028 & $\begin{array}{l}\text { co-chaperone for } \\
\text { Hsp70 proteins [59] }\end{array}$ \\
\hline HPS5 & Q9UPZ3 & 80 & Ruby-eye protein 2 & $13.5 \pm 6.2$ & $6 \pm 1.4$ & 2.25 & 9.1 & $<0.00001$ & eumelanin synthesis [60] \\
\hline LY75 & O60449 & 56 & $\begin{array}{c}\text { Lymphocyte } \\
\text { antigen } 75 \\
\text { (C-type lectin, CD205) }\end{array}$ & $62.9 \pm 23.2$ & $29.8 \pm 12.1$ & 2.14 & 5.0 & $<0.00001$ & $\begin{array}{l}\text { antigen uptake of antigen } \\
\text { presenting cells }[61,62]\end{array}$ \\
\hline GTF2H1 & P32780 & 90 & $\begin{array}{l}\text { General transcription } \\
\text { factor } I \mathrm{H} \text { subunit } 1\end{array}$ & $69.8 \pm 32.9$ & $33.8 \pm 7.9$ & 2.07 & 7.5 & $<0.00001$ & $\begin{array}{l}\text { part of DNA repair } \\
\text { complex TFIIH [63] }\end{array}$ \\
\hline SLC25A6 & P12236 & 90 & $\begin{array}{c}\text { ADP/ATP translocase } \\
3 \text { (ANT3) }\end{array}$ & $67.6 \pm 15.7$ & $32.9 \pm 8$ & 2.06 & 4.0 & 0.00008 & $\begin{array}{l}\text { cellular energy metabolism, } \\
\text { mediation of T-cell survival [64] }\end{array}$ \\
\hline ATP7A & P70705 & 90 & $\begin{array}{c}\text { Copper-transporting } \\
\text { ATPase } 1\end{array}$ & $10.6 \pm 1.6$ & $5.1 \pm 1.3$ & 2.05 & 7.6 & $<0.00001$ & $\begin{array}{l}\text { regulation of macrophage } \\
\text { function and extracellular } \\
\text { superoxide dismutase activity [65] }\end{array}$ \\
\hline DSCR3 & 014972 & 88 & $\begin{array}{l}\text { Down syndrome } \\
\text { critical region protein }\end{array}$ & $25.9 \pm 2.7$ & $12.9 \pm 1.3$ & 2.01 & 16.3 & $<0.00001$ & $\begin{array}{l}\text { part of polymeric } \\
\text { immunoglobulin receptor } \\
\text { transporter retromere } \\
\text { complex [66] }\end{array}$ \\
\hline SLC38A2 & Q5F468 & 89 & $\begin{array}{l}\text { Sodium-coupled } \\
\text { neutral amino acid } \\
\text { transporter } 2 \text { (SNAT2) }\end{array}$ & $19.3 \pm 7.9$ & $49.1 \pm 9.5$ & -2.54 & -4.8 & $<0.00001$ & $\begin{array}{l}\text { cell volume regulation, } \\
\text { response to osmotic stress } \\
\text { or amino acid depletion [67] }\end{array}$ \\
\hline
\end{tabular}

of $\mathrm{p} 62$ promotes increased transcription by binding to thyroid hormone receptors [76]. Nevertheless, upregulation of the superoxide dismutase activity modulator, ATP7A [65], suggests the need for improved DNA damage repair in response to increased oxidative insult, so that induced expression of the whole TFIIH complex cannot be ruled out (p62 might induce recruitment of other parts of this DNA repair complex [76]). The differential regulation of DNAJC12 may also reflect general transcriptional changes by maintaining the molecular function of estrogen receptors together with HSP70 [77]. Although none of the annotated HSP70 transcripts were upregulated, stress-induced increase in the activity of some HSP70s is achieved by regulating the corresponding HSP40 levels [59].

The upregulation of SLC25A6 could be expected due to its role in promoting Th cell survival [64].
Immunomodulatory role of protein M126 is an expected finding, considering that other members of S100 calgranulin family proteins have known antimicrobial antiinflammatory roles [58] and the protein is upregulated in chicken cecum after bacterial infection [54]. Similarly, upregulation of GAL2, AVID, SAA and LY75 can be expected, based on some avian immune stimulation studies $[53,61,78]$ and our general knowledge about the functions of these proteins reviewed in [55-57,62]. However the roles of AVID and SAA in avian immunity remain unclear, supposedly together having an anti-inflammatory role by suppressing cell proliferation and supplying host cells with nutrients [53,79]. Indeed, for several other upregulated transcripts or their protein family members, an antiinflammatory role has been suggested (M126, i.e. S100 calcgranulins [58], GAL2 i.e. beta-defencins [55], HPS5 [71], DSCR3 i.e. vps26 retromer complex [80]). These 
findings suggest that $12 \mathrm{~h}$ after immunostimulation, anti-inflammatory proteins already dominate at the transcriptomic level. However, while upregulation of M126, GAL2 and LY75 in avian leukocytes is expected, the transcriptional upregulation of SAA and AVID in whole blood suggest that the immune response-related transcriptional upregulation of these common acutephase proteins in the tissue can be detected. Previously the leukocyte upregulation of SAA following an immune response has been found in human blood [81]. Our results indicate that sauropsid whole blood mRNA sampling also has a diagnostic value in immunoecological studies of small vertebrates, where obtaining sufficient amount of blood for isolating leukocytes is not possible without terminal sampling.

The relative lack of shared genes with human common host response [51] compares favourably with more recent microarray studies involving in vivo immune stimulation of gilthead seabream (Sparus aurata) skeletal muscle cells, human alveolar macrophages [20] and leukocytes [82]. These studies show regulation of some INF, IL, tumour necrosis factor (TNF) and TLRs, but share only a few upregulated transcripts with our data. Similarly, comparing the list of 420 differentially expressed transcripts with 63 differentially regulated genes identified in a microarray analysis involving LPS administration of chicken liver, muscle and intestinal tissues [83] indicated 3 shared transcripts - IL8, Gallinacin (GAL) and epidermal growth factor receptor (EGFR), although 36 of them were present in the total dataset. While variations in sampling time and quantification methods contribute to these differences, the presence of some low copy-number host response genes could have been masked by the abundance of hemoglobin and other high copy-number erythrocyte transcripts. Moreover, significant inter-host variation in transcript abundance may have masked upregulation of common host response genes as over half of the human common host response genes were present in our dataset with no significant upregulation. Nevertheless, several differentially regulated transcripts have been linked to the immune response of vertebrates and birds, in particular. This, together with the considerable loss of body mass among LPS-injected birds confirms successful immune system stimulation and immune responsive nature of upregulated transcripts in our experiment.

The excess of erythrocyte transcripts in our data allows us to consider their participation in the immune response, as suggested from some in vitro studies [23,84]. In most vertebrate species the principal component of blood, erythrocytes, are nucleated, expressing proteins and mRNAs related to various physiological processes other than oxygen transport [85]. Although it has been long known that non-nucleated erythrocytes participate in an immune response [86], the issue is not well studied
[85]. Only recently it has been suggested that chicken red blood cells upregulate toll-like receptor 3 (TLR3), type I interferon's (IFN) and IL8 transcripts in response to viral dsRNA mimetic poly I:C $[23,84]$. In rainbow trout (Oncorhynchus mykiss) erythrocytes, both heat stress and in vitro incubation with LPS modulate genes related to stress, immune response, apoptosis and hematopoiesis [85,87]. Although upregulation of IL8 coincides with induced expression in chicken erythrocytes by poly I:C [23], no common transcripts with in vitro LPS stimulated rainbow trout erythrocytes [85] could be detected. Our data thus suggest that the role of nucleated erythrocytes in LPS-induced immune response in vivo is small. Comparison with other tissues is necessary to consolidate this conclusion.

Finally, we were unable to determine the extent to which differences in transcriptome expression between LPS- and saline-injected birds can be ascribed to endotoxin-induced changes in leukocyte numbers. LPS injection usually causes transient changes in the concentration of different types of circulating leukocytes [88]. In domestic chicken, the number of circulating heterophils correlates with mRNA expression of different inflammatory cytokines and chemokines at different time intervals subsequent to corticosterone administration [89]. The question as to whether and how differential gene expression relates to the profile the cellular composition of the blood in non-model species needs to be addressed, preferably correlating withinindividual changes in gene expression with corresponding changes in circulating leukocyte counts. Another limitation of our study is that the birds were sampled only at one time-point of the APR, which means that we could have missed other differentially expressed transcripts that appear before and after the $12 \mathrm{~h}$ time-point of sampling. Such issues can be addressed by multiple time-point measurements in future studies. Preferably along with increased sequencing depth.

\section{Conclusions}

In passerines, detecting upregulation of antimicrobial defences during acute phase response can be achieved by quantifying whole blood mRNA of SAA, AVID, M126 or GAL2. Quantifying these transcripts along with a selection of housekeeping genes, should provide reliable biomarkers to estimate immune system activation from small blood samples, i.e., in situations where non-terminal sampling is required and only small amounts of tissue can be collected. We also provide the first transcriptome sequencing data of greenfinches, facilitating integration of genomic tools into research involving this species.

\section{Availability of supporting data}

The data sets supporting the results of this article are included within the article and its additional file and 
available in the DDBJ/EMBL/GenBank under the accession GBCG00000000 (http://www.ncbi.nlm.nih.gov/nuccore/ GBCG00000000).

\section{Additional file}

Additional file 1: Table S1. Full list of annotated transcripts, expression values, test statistics and fold changes. RPKM values for both treatment groups are given with SD. For each assembled contig annotation with both Uniprot-Swissprot and NCBI- non-redundant database is shown if present. Not all contigs had a match in both databases.

\section{Competing interests}

The authors declare that they have no competing interests.

\section{Authors' contributions}

RM conceived the study and participated in its design, preformed the annotations, carried out the analyses, and drafted the manuscript. RA participated in the design of the study and helped to draft the manuscript. $\mathrm{PH}$ participated in the design of the study and coordination and helped to draft the manuscript. All authors read and approved the final manuscript.

\section{Acknowledgements}

We thank Tuul Sepp, Ulvi Karu, Marju Männiste, and Mari-Ann Lind for help with bird maintenance, experiments and biochemical analyses. Two anonymous reviewers provided constructive criticism on the ms. The study was financed by the Estonian Ministry of Education and Science (target-financing project \# 0180004 s09) and by the European Union through the European Regional Development Fund (Centre of Excellence FIBIR). RA was supported by SF0180026s09 from the Estonian Ministry of Education and Research and by the EU ERDF through the Estonian Centre of Excellence in Genomics.

\section{Author details}

'Department of Zoology, Institute of Ecology and Earth Sciences, Tartu University, Vanemuise 46, 51014 Tartu, Estonia. ${ }^{2}$ Department of Bioinformatics, Institute of Molecular and Cell Biology, University of Tartu, Riia 23, 51010 Tartu, Estonia.

Received: 8 April 2014 Accepted: 24 June 2014

Published: 27 June 2014

\section{References}

1. Schmid-Hempel P: Evolutionary Parasitology. The Integrated Study of Infections, Immunology, Ecology, and Genetics. New York: Oxford University Press; 2011

2. Wilson $\mathrm{K}$, Cotter SC: Host-parasite interactions and the evolution of immune defense. Adv Study Behav 2013, 45:81-174.

3. Jackson JA, Begon M, Birtles R, Paterson S, Friberg IM, Hall A, Ralli C, Turner A, Zawadzka M, Bradley JE: The analysis of immunological profiles in wild animals: a case study on immunodynamics in the field vole, Microtus agrestis. Mol Ecol 2011, 20(5):893-909.

4. Pedersen AB, Babayan SA: Wild immunology. Mol Ecol 2011, 20(5):872-880

5. Demas GE, Nelson RJ: Ecoimmunology. New York: Oxford University Press; 2011.

6. Schulenburg H, Kurtz J, Moret Y, Siva-Jothy MT: Introduction. Ecological immunology. Philos Trans R Soc B: Biol Sci 2009, 364:3-14.

7. Sheldon $B C$, Verhulst S: Ecological immunology: costly parasite defences and trade-offs in evolutionary ecology. Trends Ecol Evol 1996, 11:317-321.

8. Ellegren $\mathrm{H}$, Sheldon $\mathrm{BC}$ : Genetic basis of fitness differences in natural populations. Nature 2008, 452(7184):169-175.

9. Peterson M, Whittaker D, Ambreth S, Sureshchandra S, Buechlein A, Podicheti R, Choi J-H, Lai Z, Mockatis K, Colbourne J, Tang H, Ketterson E: De novo transcriptome sequencing in a songbird, the dark-eyed junco (Junco hyemalis): genomic tools for an ecological model system. BMC Genomics 2012, 13(1):305.

10. Bouck $A$, Vision $\mathrm{T}$ : The molecular ecologist's guide to expressed sequence tags. Mol Ecol 2007, 16(5):907-924.

11. Künstner A, Wolf JBW, Backström N, Whitney O, Balakrishnan CN, Day L, Edwards SV, Janes DE, Schlinger BA, Wilson RK, Jarvis ED, Warren WC,
Ellegren $\mathrm{H}$ : Comparative genomics based on massive parallel transcriptome sequencing reveals patterns of substitution and selection across 10 bird species. Mol Ecol 2010, 19(SUPPL. 1):266-276.

12. Feldmeyer B, Wheat CW, Krezdorn N, Rotter B, Pfenninger M: Short read Illumina data for the de novo assembly of a non-model snail species transcriptome (Radix balthica, Basommatophora, Pulmonata), and a comparison of assembler performance. BMC Genomics 2011 12(1):317.

13. Santure AW, Gratten J, Mossman JA, Sheldon BC, Slate J: Characterisation of the transcriptome of a wild great tit Parus major population by next generation sequencing. BMC Genomics 2011, 12:283.

14. Srivastava A, Winker K, Shaw Tl, Jones KL, Glenn TC: Transcriptome analysis of a North American songbird, melospiza melodia. DNA Res 2012, 19(4):325-333.

15. Subramanian S, Huynen L, Millar CD, Lambert DM: Next generation sequencing and analysis of a conserved transcriptome of New Zealand's kiwi. BMC Evol Biol 2010, 10(1):387.

16. Wang Z, Gerstein M, Snyder M: RNA-Seq: a revolutionary tool for transcriptomics. Nat Rev Genet 2009, 10(1):57-63.

17. Webster LMI, Paterson S, Mougeot F, Martinez-Padilla J, Piertney SB: Transcriptomic response of red grouse to gastro-intestinal nematode parasites and testosterone: implications for population dynamics. Mol Ecol 2011, 20(5):920-931.

18. Oshlack A, Chabot AE, Smyth GK, Gilad Y: Using DNA microarrays to study gene expression in closely related species. Bioinformatics 2007 23(10):1235-1242.

19. Whitehead A, Crawford DL: Variation within and among species in gene expression: raw material for evolution. Mol Ecol 2006, 15(5):1197-1211.

20. Kaitetzidou E, Crespo D, Vraskou Y, Antonopoulou E, Planas JV: Transcriptomic Response of Skeletal Muscle to Lipopolysaccharide in the Gilthead Seabream (Sparus aurata). Mar Biotechnol 2012, 14(5):605-619.

21. Martin LB, Kidd L, Liebl AL, Coon CAC: Captivity induces hyperinflammation in the house sparrow (Passer domesticus). J Exp Biol 2011, 214(15):2579-2585.

22. Naidu KS, Morgan LW, Bailey MJ: Inflammation in the avian spleen: timing is everything. BMC Mol Biol 2010, 11(1):104.

23. St Paul M, Paolucci S, Barjesteh N, Wood RD, Sharif S: Chicken erythrocytes respond to Toll-like receptor ligands by up-regulating cytokine transcripts. Res Vet Sci 2013, 95(1):87-91.

24. Vinkler M, Svobodová J, Gabrielová B, Bainová H, Bryjová A: Cytokine expression in phytohaemagglutinin-induced skin inflammation in a galliform bird. J Avian Biol 2014, 45:43-50.

25. Bonneaud C, Balenger SL, Russell AF, Zhang J, Hill GE, Edwards SV: Rapid evolution of disease resistance is accompanied by functional changes in gene expression in a wild bird. Proc Natl Acad Sci 2011 108(19):7866-7871

26. Pemberton J, Beraldi D, Craig B, Hopkins J: Digital gene expression analysis of gastrointestinal helminth resistance in Scottish blackface lambs. Mol Ecol 2011, 20(5):910-919.

27. Barker FK, Cibois A, Schikler P, Feinstein J, Cracraft J: Phylogeny and diversification of the largest avian radiation. Proc Natl Acad Sci U S A 2004, 101(30):11040-11045.

28. Eley C: Status Signalling In The Western Greenfinch (Carduelis chloris). PhD thesis. Brighton: University of Sussex; 1991

29. Lindström K, Lundström J: Male greenfinches (Carduelis chloris) with brighter ornaments have higher virus infection clearance rate. Behav Ecol Sociobiol 2000, 48:44-51.

30. Männiste $M$, Hõrak P: Emerging infectious disease selects for darker plumage coloration in greenfinches. Front Ecol Evol 2014, 2:4.

31. Merilä J, Sheldon BC, Lindström K: Plumage brightness in relation to haematozoan infections in the greenfinch Carduelis chloris : Bright males are a good bet. Ecoscience 1999, 6(1):12-18.

32. Sepp T, Sild E, Hõrak P: Hematological Condition Indexes in Greenfinches: Effects of Captivity and Diurnal Variation. Physiol Biochem Zool 2010, 83(2):276-282

33. Peters A, Delhey $K$, Andersson S, van Noordwijk H, Forschler Ml: Condition-dependence of multiple carotenoid-based plumage traits: an experimental study. Funct Ecol 2008, 22:831-839.

34. Aguilera $E$, Amat J: Carotenoids, immune response and the expression of sexual ornaments in male greenfinches (Carduelis chloris).

Naturwissenschaften 2007, 94:895-902 
35. Sarv T, Hõrak P: Phytohaemagglutinin injection has a long-lasting effect on immune cells. J Avian Biol 2009, 40(5):569-571.

36. Lindström K, Krakower D, Lundström JO, Silverin B: The effects of testosterone on a viral infection in greenfinches (Carduelis chloris): an experimental test of the immunocompetence-handicap hypothesis. Proc R Soc Lond Ser B Biol Sci 2001, 268:207-211.

37. Sepp T, Karu U, Blount JD, Sild E, Männiste M, Hörak P: Coccidian Infection Causes Oxidative Damage in Greenfinches. PLOS ONE 2012, 7(5):e36495.

38. Meitern R, Sild E, Kilk K, Porosk R, Hõrak P: On the methodological limitations of detecting oxidative stress: effects of paraquat on measures of oxidative status in greenfinches. J Exp Biol 2013, 216(14):2713-2721.

39. Lilliendahl K: Daily accumulation of body reserves under increased predation risk in captive Greenfinches Carduelis chloris. Ibis 2000, 142:587-595.

40. Herborn KA, Coffey J, Larcombe SD, Alexander L, Arnold KE: Oxidative profile varies with personality in European greenfinches. J Exp Biol 2011, 214(10):1732-1739.

41. Hegemann A, Matson KD, Versteegh MA, Villegas A, Tieleman BI: Immune response to an endotoxin challenge involves multiple immune parameters and is consistent among the annual-cycle stages of a free-living temperate zone bird. J Exp Biol 2013, 216(14):2573-2580.

42. King MO, Swanson DL: Activation of the immune system incurs energetic costs but has no effect on the thermogenic performance of house sparrows during acute cold challenge. J Exp Biol 2012, 216(11):2097-2102.

43. Iseri VJ, Klasing KC: Dynamics of the systemic components of the chicken (Gallus gallus domesticus) immune system following activation by Escherichia coli; implications for the costs of immunity. Dev Comp Immunol 2013, 40(3-4):248-257.

44. Meitern R, Sild E, Lind M-A, Männiste M, Sepp T, Karu U, Hörak P: Effects of Endotoxin and Psychological Stress on Redox Physiology, Immunity and Feather Corticosterone in Greenfinches. PLOS ONE 2013, 8(6):e67545.

45. Chiari Y, Galtier N: RNA extraction from sauropsids blood: evaluation and improvement of methods. Amphibia-Reptilia 2011, 32(1):136-139.

46. Grabherr MG, Haas BJ, Yassour M, Levin JZ, Thompson DA, Amit I, Adiconis $X$, Fan L, Raychowdhury R, Zeng Q: Full-length transcriptome assembly from RNA-Seq data without a reference genome. Nat Biotechnol 2011, 29(7):644-652

47. Zhao $Y$, Tang $H$, Ye Y: RAPSearch2: a fast and memory-efficient protein similarity search tool for next-generation sequencing data. Bioinformatics 2012, 28(1):125-126

48. McCarthy FM, Bridges SM, Wang N, Magee GB, Williams WP, Luthe DS, Burgess SC: AgBase: A unified resource for functional analysis in agriculture. Nucleic Acids Res 2007, 35(SUPPL. 1):D599-D603.

49. Altschul SF, Gish W, Miller W, Myers EW, Lipman DJ: Basic local alignment search tool. J Mol Biol 1990, 215(3):403-410

50. Parra G, Bradnam K, Korf I: CEGMA: a pipeline to accurately annotate core genes in eukaryotic genomes. Bioinformatics 2007, 23(9):1061-1067.

51. Jenner RG, Young RA: Insights into host responses against pathogens from transcriptional profiling. Nat Rev Microbiol 2005, 3(4):281-294.

52. Baggerly KA, Deng L, Morris JS, Aldaz CM: Differential expression in SAGE: accounting for normal between-library variation. Bioinformatics 2003, 19(12):1477-1483.

53. Matulova M, Rajova J, Vlasatikova L, Volf J, Stepanova H, Havlickova H, Sisak F, Rychlik I: Characterization of Chicken Spleen Transcriptome after Infection with Salmonella enterica Serovar Enteritidis. PLOS ONE 2012, 7(10): 448101.

54. Matulova M, Varmuzova K, Sisak F, Havlickova H, Babak V, Stejskal K, Zdrahal Z, Rychlik I: Chicken innate immune response to oral infection with Salmonella enterica serovar Enteritidis. Vet Res 2013, 44(1):37.

55. Cuperus T, Coorens M, van Dijk A, Haagsman HP: Avian host defense peptides. Dev Comp Immunol 2013, 41(3):352-369.

56. Tuohimaa P, Joensuu T, Isola J, Keinänen R, Kunnas T, Niemelä A, Pekki A, Wallén M, Ylikomi T, Kulomaa M: Development of progestin-specific response in the chicken oviduct. Int J Dev Biol 1989, 33(1):125-134.

57. Uhlar CM, Whitehead AS: Serum amyloid $A$, the major vertebrate acute-phase reactant. Eur J Biochem 1999, 265(2):501-523.

58. Hsu K, Champaiboon C, Guenther BD, Sorenson BS, Khammanivong A, Ross KF, Geczy CL, Herzberg MC: Anti-infective protective properties of S100 calgranulins. Anti-Inflammatory Anti-Allergy Agents Med Chem 2009, 8(4):290-305.
59. Qiu XB, Shao YM, Miao S, Wang L: The diversity of the DnaJ/Hsp40 family, the crucial partners for Hsp70 chaperones. Cell Mol Life Sci 2006, 63(22):2560-2570.

60. Hirobe T, Wakamatsu K, Ito S: A new mutation of mouse ruby-eye 2, $\mathrm{ru2d/hps5}$ ru2-d inhibits eumelanin synthesis but stimulates pheomelanin synthesis in melanocytes. Zool Sci 2012, 29(10):652-661.

61. Staines K, Young JR, Butter C: Expression of Chicken DEC205 Reflects the Unique Structure and Function of the Avian Immune System. PLOS ONE 2013, 8(1):e51799.

62. Figdor CG, Van Kooyk Y, Adema GJ: C-type lectin receptors on dendritic cells and langerhans cells. Nat Rev Immunol 2002, 2(2):77-84.

63. Compe E, Egly JM: TFIIH: When transcription met DNA repair. Nat Rev Mol Cell Biol 2012, 13(6):343-354.

64. Jang J-Y, Lee C-E: IL-4-induced upregulation of adenine nucleotide translocase 3 and its role in Th cell survival from apoptosis. Cell Immunol 2006, 241(1):14-25.

65. Kim HW, Chan Q, Afton SE, Caruso JA, Lai B, Weintraub NL, Qin Z: Human macrophage ATP7A is localized in the trans-Golgi apparatus, controls intracellular copper levels, and mediates macrophage responses to dermal wounds. Inflammation 2012, 35(1):167-175.

66. Vergés M, Luton F, Gruber C, Tiemann F, Reinders LG, Huang L, Burlingame $A L$, Haft CR, Mostov KE: The mammalian retromer regulates transcytosis of the polymeric immunoglobulin receptor. Nat Cell Biol 2004, 6(8):763-769.

67. Franchi-Gazzola R, Dall'Asta V, Sala R, Visigalli R, Bevilacqua E, Gaccioli F, Gazzola GC, Bussolati O: The role of the neutral amino acid transporter SNAT2 in cell volume regulation. Acta Physiol 2006, 187(1-2):273-283.

68. McGettigan PA: Transcriptomics in the RNA-seq era. Curr Opin Chem Biol 2013, 17(1):4-11.

69. Schatz MC, Delcher AL, Salzberg SL: Assembly of large genomes using second-generation sequencing. Genome Res 2010, 20(9):1165-1173.

70. Stockhammer OW, Zakrzewska A, Hegedûs Z, Spaink HP, Meijer AH: Transcriptome profiling and functional analyses of the zebrafish embryonic innate immune response to salmonella infection. J Immunol 2009, 182(9):5641-5653.

71. Wei ML: Hermansky-Pudlak syndrome: a disease of protein trafficking and organelle function. Pigment Cell Res 2006, 19(1):19-42.

72. Huizing M, Hess R, Dorward H, Claassen DA, Helip-Wooley A, Kleta R, Kaiser-Kupfer MI, White JG, Gahl WA: Cellular, molecular and clinical characterization of patients with Hermansky-Pudlak syndrome type 5 . Traffic 2004, 5(9):711-722.

73. Doyle EL, Ridger V, Ferraro F, Turmaine M, Saftig P, Cutler DF: CD63 is an essential cofactor to leukocyte recruitment by endothelial P-selectin. Blood 2011, 118(15):4265-4273.

74. Ducrest AL, Keller L, Roulin A: Pleiotropy in the melanocortin system, coloration and behavioural syndromes. Trends Ecol Evol 2008, 23(9):502-510.

75. Hyde R, Cwiklinski EL, MacAulay K, Taylor PM, Hundal HS: Distinct Sensor Pathways in the Hierarchical Control of SNAT2, a Putative Amino Acid Transceptor, by Amino Acid Availability. J Biol Chem 2007, 282(27):19788-19798.

76. Liu Y, Ando S, Xia X, Yao R, Kim M, Fondell J, Yen PM: p62, a TFIIH subunit, directly interacts with thyroid hormone receptor and enhances T3-mediated transcription. Mol Endocrinol 2005, 19(4):879-884.

77. Terada K, Yomogida K, Imai T, Kiyonari H, Takeda N, Kadomatsu T, Yano M, Aizawa S, Mori M: A type I DnaJ homolog, DjA1, regulates androgen receptor signaling and spermatogenesis. EMBO J 2005, 24(3):611-622.

78. Kunnas TA, Wallén MJ, Kulomaa MS: Induction of chicken avidin and related mRNAs after bacterial infection. Biochim Biophys Acta(BBA)-Gene Struct Expr 1993, 1216(3):441-445.

79. Zerega B, Pagano A, Pianezzi A, Ulivi V, Camardella L, Cancedda R, Cancedda FD: Expression of Serum Amyloid A in chondrocytes and myoblasts differentiation and inflammation: Possible role in cholesterol homeostasis. Matrix Biol 2004, 23(1):35-46.

80. Zhou B, Yun EY, Ray L, You J, Ip YT, Lin X: Retromer promotes immune quiescence by suppressing Spätzle-Toll pathway in Drosophila. J Cell Physiol 2014, 229(4):512-520.

81. Talwar S, Munson PJ, Barb J, Fiuza C, Cintron AP, Logun C, Tropea M, Khan S, Reda D, Shelhamer JH, Danner RL, Suffredini AF: Gene expression profiles of peripheral blood leukocytes after endotoxin challenge in humans. Physiol Genomics 2006, 25(2):203-215. 
82. Reynier F, de Vos AF, Hoogerwerf JJ, Bresser P, van der Zee JS, Paye M, Pachot A, Mougin B, van der Poll T: Gene expression profiles in alveolar macrophages induced by lipopolysaccharide in humans. Mol Med 2012, 18(9):1303-1311.

83. Baurhoo B, Ferket P, Ashwell CM, de Oliviera J, Zhao X: Cell walls of Saccharomyces cerevisiae differentially modulated innate immunity and glucose metabolism during late systemic inflammation. PLOS ONE 2012, 7(1):e30323.

84. Morera D, Roher N, Ribas L, Balasch JC, Doñate C, Callol A, Boltaña S, Roberts S, Goetz G, Goetz FW: RNA-seq reveals an integrated immune response in nucleated erythrocytes. PLOS ONE 2011, 6(10):e26998.

85. Morera D, MacKenzie SA: Is there a direct role for erythrocytes in the immune response. Vet Res 2011, 42:89.

86. Siegel I, Lin Liu T, Gleicher N: The red-cell immune system. Lancet 1981 318(8246):556-559.

87. Lewis JM, Hori TS, Rise ML, Walsh PJ, Currie S: Transcriptome responses to heat stress in the nucleated red blood cells of the rainbow trout (Oncorhynchus mykiss). Physiol Genomics 2010, 42(3):361-373.

88. Wang W, Wideman RF Jr, Chapman ME, Bersi TK, Erf GF: Effect of intravenous endotoxin on blood cell profiles of broilers housed in cages and floor litter environments. Poult Sci 2003, 82(12):1886-1897.

89. Shini S, Shini A, Kaiser P: Cytokine and chemokine gene expression profiles in heterophils from chickens treated with corticosterone. Stress Int J Biol Stress 2010, 13(3):185-194.

doi:10.1186/1471-2164-15-533

Cite this article as: Meitern et al:: Profile of whole blood gene expression following immune stimulation in a wild passerine. BMC Genomics 2014 15:533.

\section{Submit your next manuscript to BioMed Central and take full advantage of:}

- Convenient online submission

- Thorough peer review

- No space constraints or color figure charges

- Immediate publication on acceptance

- Inclusion in PubMed, CAS, Scopus and Google Scholar

- Research which is freely available for redistribution 